\title{
High intraepithelial expression of estrogen and progesterone receptors in the transformation zone of the uterine cervix
}

\author{
Franck Remoue ${ }^{1}, \mathrm{PhD}$, Nathalie Jacobs ${ }^{1}, \mathrm{PhD}$, Valerie Miot, BA, Jacques Boniver, MD, PhD, and Philippe
} Delvenne, $\mathrm{MD}, \mathrm{PhD}$

From the Department of Pathology, University of Liege, Liege, Belgium

\begin{abstract}
OBJECTIVE: Because sex hormones may be involved in tumor initiation and progression, we analyzed the presence of hormone receptors in the transformation zone of the uterine cervix where the majority of human papillomavirus infections and associated (pre)neoplastic lesions develop.

STUDY DESIGN: By using 23 total hysterectomy samples from young women who underwent surgery for noncervical benign uterine disease, we analyzed, by immunohistologic techniques, the in situ expression of estrogen $\left(\mathrm{E}_{2}-\mathrm{R}\right)$ and progesterone $\left(\mathrm{P}_{4}-\mathrm{R}\right)$ receptors in the transformation zone and ectocervix of the same women. RESULTS: The expression of estrogen receptors and progesterone receptors is significantly higher in the transformation zone compared with the ectocervix. Immunohistochemical localization indicated that hormone receptor-positive cells are mainly observed in (para)basal and intermediate cell layers in both the transformation zone and ectocervical epithelium. When transformation zone samples were segregated into epithelial tissues with a predominantly mature ( $7 / 23$ samples) or immature (16/23 samples) squamous metaplasia, only biopsy specimens with immature squamous metaplasia showed a significantly higher density of hormone receptorpositive cells compared with ectocervical epithelium $(\mathrm{P}<.01)$.

CONCLUSION: Our results suggest that the cervical transformation zone may be at increased risk of the development of cancer because of a high sensitivity to sex hormone regulation.
\end{abstract}

Key words: Transformation zone, hormone receptor, uterine cervix, cancer

A substantial majority of cancers and precursor lesions (squamous intraepithelial lesions; SILs) develop within a specific region of the cervix, the transformation zone (TZ), ${ }^{1}$ where the glandular epithelium of the endocervix is transformed progressively into a squamous epithelium during a process called metaplasia, which can be considered as a stepwise progression of changes. In the first phase, endocervical "reserve" cells proliferate and stratify. ${ }^{2}$ After, these cells differentiate into squamous cells that initially have only a slightly increased amount of cytoplasm and which undermine the endocervical epithelium that is often seen as a residual layer on the surface (immature squamous metaplasia). Later, the cells may mature fully to squamous cells that are indistinguishable from the superficial cells of the ectocervix. ${ }^{3}$

The chronic infection of metaplastic keratinocytes of the TZ by oncogenic types of human papillomavirus (HPV) is associated with the induction of SIL, which may result in the development of cervical invasive cancer. ${ }^{4}$

Despite the evidence that HPV is implicated strongly as the causative agent of cervical cancer, HPV infection alone is not sufficient for SIL development. In addition to immune, microbial, or chemical cofactors, ${ }^{5-7}$ sex hormones may play a role in the development of SIL. Indeed, the variation of hormonal status that depends on age, pregnancy, or contraceptive use, has been shown to influence the development of cervical (pre)neoplastic lesions. ${ }^{8-10}$ Interestingly, the topography and natural history of the cervical TZ are also affected by age, hormonal status, and parity. ${ }^{11}$ For example, the mechanism by which the original squamocolumnar junction changes location after the onset of puberty may be a mechanical one that is caused by the swelling of the cervical stroma in response to hormonal stimulation; pregnancy has been shown to be associated with more endocervical tissue moving out onto the ectocervix. ${ }^{3}$ Moreover, it has been demonstrated, in HPV16 transgenic mice models, that estrogen exposure is involved in the particular sensitivity of the TZ to SIL development. ${ }^{12,13}$

These effects of sex hormones could be explained, in part, by their property to induce HPV gene expression through hormone response elements in the viral genome. ${ }^{14}$ Direct and indirect effects have been described previously. ${ }^{14,15}$ Accordingly, the expression of estrogen $\left(E_{2}-R\right)$ and progesterone $(P 4-R)$ receptors in human

\footnotetext{
${ }^{1}$ F. R. and N. J. contributed equally to this work.
} 
cervical biopsy specimens has been shown to be higher in the stroma of low- and high-grade SIL, compared with normal ectocervix suggesting an indirect interaction between hormone receptors and HPV genome. ${ }^{15}$ However, the function of sex hormone receptors in neoplastic lesions of the cervix remains unclear. The positive rates of $\mathrm{E}_{2}-\mathrm{R}$ and $\mathrm{P} 4-\mathrm{R}$ were found to be lower in cervical invasive neoplasia ${ }^{15,16}$ and established squamous carcinoma of the cervix are not influenced markedly by steroids. ${ }^{17}$

By using total hysterectomy samples from young women who underwent surgery for noncervical benign uterine disease, we analyzed, by immunohistologic techniques, the in situ expression of $E_{2}-R$ and $P_{4}-R$ in the $T Z$ and ectocervix of the same women. Our results suggest that the TZ may be at increased risk of developing (pre)neoplastic lesions because of a high sensitivity to sex hormone regulation.

\section{MATERIAL AND METHODS}

\section{Biopsy specimens.}

Twenty-three cervices from women who underwent total hysterectomy for noncervical benign uterine disease were analyzed in this study. These cases were retrieved from the files of the Pathology Department of University Hospital of Liège, Belgium, on the basis of histologic findings and a previous normal Papanicolaou test that was obtained shortly before surgery. Only paraffin blocks that showed histologic evidence of both ecto-cervical and TZ epithelium/stroma were selected. The TZ samples were divided into tissues with a predominantly mature (7/23 specimens, $30 \%$ ) or immature (16/23 specimens, $70 \%)$ squamous metaplasia.

The mean age of the women was 36.4 years (range, 30-41 years), and none of them were menopausal. The phase of menstrual cycle was determined systematically by endometrial histologic evidence and was categorized as either proliferative or secretory.

\section{Immunohistochemical staining of $E_{2}-R$ and $P_{4}-R$.}

From paraffin-embedded biopsy specimens, sections $(5-10 \mu \mathrm{m})$ were rehydrated, and endogenous peroxidase was blocked with 3\% hydrogen peroxide in methanol for 10 minutes. The sections were then permeabilized with citric buffer and phosphate-buffered saline solution and $0.1 \%$ Tween for 20 minutes. The slides were incubated for 2 hours with mouse monoclonal to anti-human $\mathrm{E}_{2}-\mathrm{R}$ (clone 1D5, specific for the estrogen receptor $a$.) and $\mathrm{P}_{4^{-}}$ $\mathrm{R}$ (clone PgR 636, specific for the $\alpha$ and $\beta$ forms of progesterone receptor; Dako, Carpinteria, Calif). After being washed, the peroxidase-conjugated anti-mouse antibodies (Dako) were incubated for 30 minutes and visualized with diaminobenzidine (Dako) for 10 minutes. The reaction was stopped with distilled water, and slides were counter-stained with hematoxylin.

Positive (from breast cancer biopsy specimens) and negative (irrelevant antibody; Dako) control slides were used for each immunohistochemical staining.

\section{Immunohistochemical staining of Ki-67 antigen.}

Five-micrometer sections of the biopsy specimens were deparaffinized, rehydrated, and incubated with $0.05 \%$ trypsin in TRIS-buffered saline solution (TBS) for 20 minutes at $37^{\circ} \mathrm{C}$. After enzyme digestion, slides were rinsed in TBS. Antigen retrieval was then performed: the slides were treated for 15 minutes at $720 \mathrm{~W}$ in citrate buffer $(10 \mathrm{mmol} / \mathrm{L}, \mathrm{pH} 6.0)$ in a microwave oven. After being washed in TBS, sections were blocked with normal rabbit serum for 30 minutes and incubated at room temperature for 60 minutes with the MIB-1 monoclonal antibody that is specific for Ki-67 antigen (Dako, Golstrup, Denmark) that was diluted 1:80 in TBS. The slides were then washed in TBS and incubated at room temperature for 30 minutes with a biotinylated rabbit anti-mouse monoclonal antibody (1:200; Dako). After another washing step, localization of the antibodies was performed with the avidin biotin complex method with alkaline phosphatase as enzyme (Dako) and new fuschin as chromogen. The sections finally were counterstained with hematoxylin and mounted for light microscopy.

\section{Evaluation of immunohistochemical staining.}

The immunostaining was evaluated by two independent observers with the Image Pro plus software (version 4.5.0.19; Media Cybernetics Inc, Gleichen, Germany), which was found to be useful to divide off the fields and to tag the cells. Briefly, the percentages of positive cells in the TZ and ectocervical compartments were determined precisely by randomly selecting five fields in the epithelium and stroma of TZ and ectocervical regions and by counting 200 cells/field at x400 magnification. In epithelial fields, 200 cells that are in the whole 
thickness of the squamous epithelium were designated as positive or negative, whereas the same number of cells was counted randomly in the subepithelial stroma.

\section{Statistical analysis.}

The nonparametric Mann-Whitney $U$ test was used to compare labeled cells between the ectocervix and TZ with mature or immature squamous metaplasia; differences were considered to be significant at a probability value of $<.05$.

\section{RESULTS}

E2-R and $\mathrm{P}_{4}-\mathrm{R}$ expression in the TZ.

Figs 1 and 2 show the percentages of $E_{2}-R$ and $P_{4}-R$ positive cells in the epithelium and stroma of ectocervix and TZ with mature and immature squamous metaplasia. A significantly higher expression of both receptors was observed in the epithelial $(P<.01)$ and stromal $\left(\mathrm{E}_{2}-\mathrm{R}[P<.01] ; \mathrm{P}_{4}-\mathrm{R}[P<.05]\right)$ compartments of $\mathrm{TZ}$ with immature squamous metaplasia compared with ectocervix (Figs 1, $B$, and 2, $B$ ). These differences were observed for each receptor, both in the proliferative and secretory phases of menstrual cycle (data not shown). The hormone receptor expression was not significantly different between the ectocervix and the TZ with mature metaplasia (Figs 1, A, and 2, A).

Immunohistochemical localization of $\mathrm{E}_{2}-\mathrm{R}$ (Fig 3, $A$ and $B$ ) and $\mathrm{P}_{4}-\mathrm{R}$ (Fig 3, $\mathrm{C}$ and $D$ ) in the epithelial compartment indicated that labeled cells are observed mainly in (para) basal and intermediate cell layers in both $\mathrm{TZ}$ and ectocervical epithelial tissues.

\section{No absolute correlation between sex hormone receptor expression and cell proliferation.}

To determine whether sex hormone receptors are expressed predominantly in proliferating cells, we compared the localization of $E_{2}-\mathrm{R}, \mathrm{P}_{4}-\mathrm{R}$, and $\mathrm{Ki}-67$ positive cells in ectocervix and TZ biopsy specimens. Expression of Ki67 antigen was confined exclusively to the parabasal and basal cell layers of both ectocervical and metaplastic cervical epithelium, and no quantitative difference was observed between $\mathrm{TZ}$ and ectocervix (data not shown). Although $\mathrm{E}_{2}-\mathrm{R}$ and $\mathrm{P}_{4}-\mathrm{R}$ positive cells were detected in parabasal and basal cell layers, they were also demonstrated in intermediate cell layers in both localizations, which suggests the absence of an absolute correlation between steroid receptor expression and cell proliferation.

Fig 1: Percentages of estrogen receptor positive cells in the epithelium and stroma of paired tissues of ectocervix (Ecto) and TZ with (A) mature (MM) and (B) immature (IM) squamous metaplasia. NS, Not significant; two asterisks, $P<.01$.

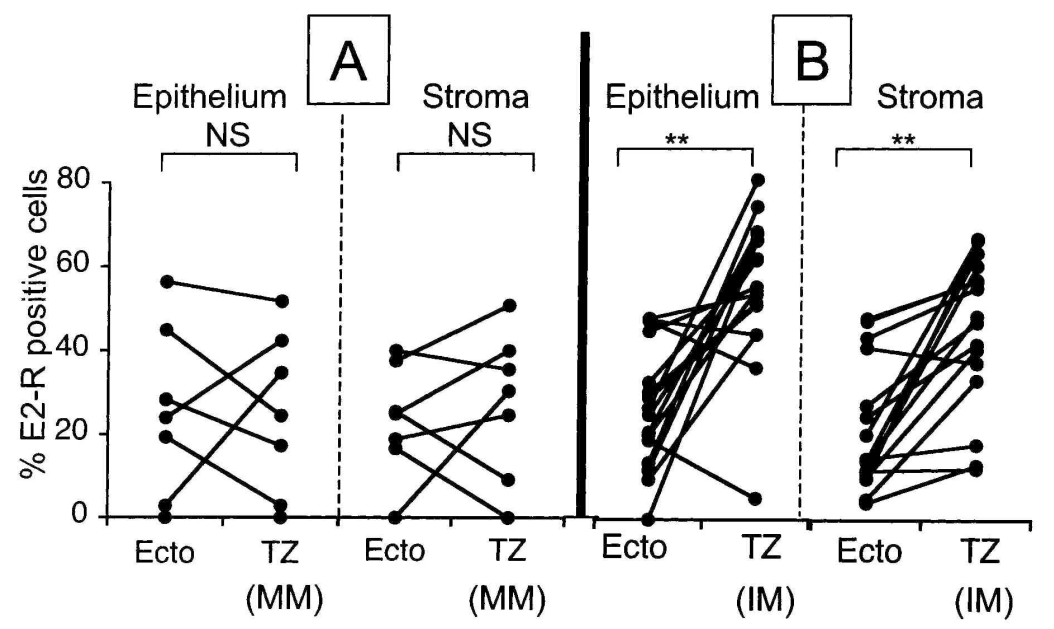


Fig 2: Percentages of progesterone receptor positive cells in the epithelium and stroma of paired tissues of ectocervix (Ecto) and TZ with (A) mature (MM) and (B) immature (IM) squamous metaplasia. NS, Not significant; two asterisks, $P<.01$; asterisk, $P<.05$.

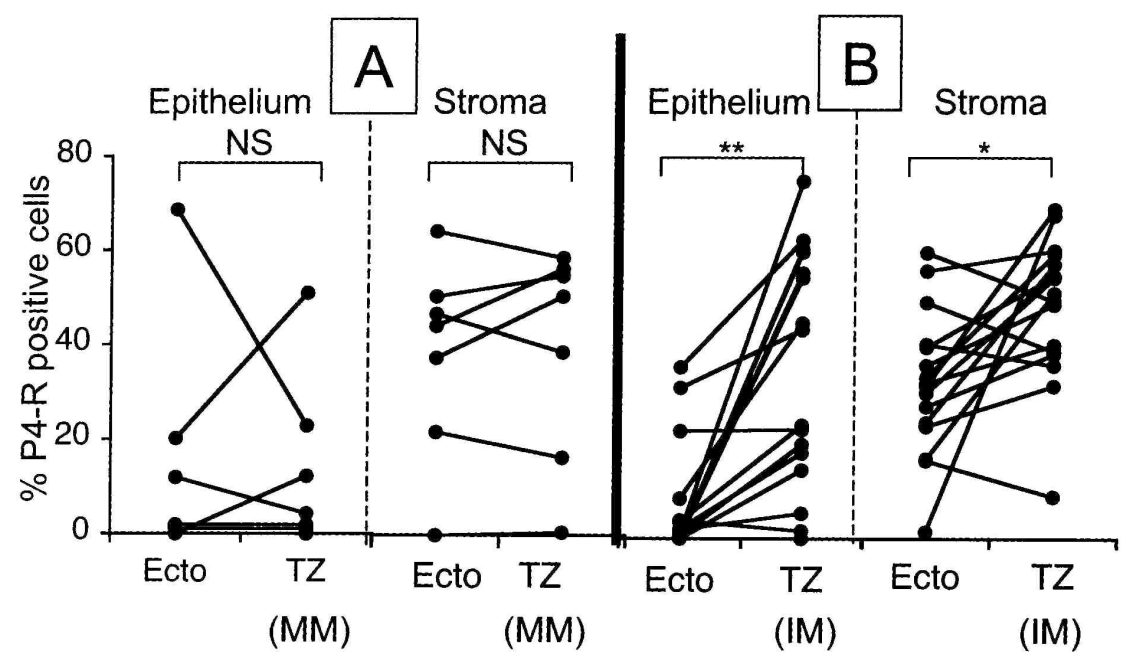

\section{COMMENT}

Several hypotheses have been proposed to explain the reason that cervical cancer, one of the most frequent causes of death in women worldwide, ${ }^{18}$ develops in the TZ of the uterine cervix, a small area of a few square millimeters. A first explanation for the increased sensitivity of the TZ to cervical (pre) neoplastic lesions is that the target cells for HPV infection, which presumably are present in the basal cell layers of the epithelium, ${ }^{6,19}$ may be mechanically more accessible in metaplastic areas in which monostratified glandular and pluristratified squamous epithelial tissues coexist ("mechanical accessibility" theory). Another possible explanation is that the keratinocytes of the TZ, because of their immature state, are deprived of a putative repression mechanism of the promoter of HPV oncogene expression. Accordingly, Sun et $\mathrm{al}^{20}$ showed that endocervical cells that were immortalized by HPV16 E6/E7 oncogenes form higher grade dysplasia in organotypic cultures than immortalized ectocervical keratinocytes. The inability of the cells that are derived from the TZ to control the viral oncogene expression could contribute to cervical neoplasia development and explain the reason that HPVassociated lesions developed in the cervix, outside of the TZ, and elsewhere in the genital tract (eg, vagina, vulva) are less susceptible to progress to cancer than those lesions that develop in the TZ. Other endogenous factors might also be involved in the sensitivity of the TZ to SIL development. Using mice that are transgenic for HPV16, some investigators have shown that the TZ is five times more sensitive to the induction of squamous cell carcinogenesis by estrogen exposure compared with other sites of the reproductive tract. ${ }^{12}$

In the current study, we have demonstrated, for the first time, a higher density of estrogen and progesterone receptor-positive cells in the epithelium and stroma of $\mathrm{TZ}$ with immature squamous metaplasia compared with ectocervix, which suggests that the $\mathrm{TZ}$ area in which the endocervical columnar epithelium is actively replaced by a pluristratified squamous epithelium has a higher sensitivity to sex hormone regulation. Our findings are in agreement with a recent study that shows that estrogens are involved directly in the process of squamous metaplasia in human TZ tissues that were implanted in mice with severe combined immunodeficiency ${ }^{13}$ These data, which are associated with the observation that the topography of the cervical TZ is also affected by the hormonal status of women, ${ }^{11}$ suggest that this region of the cervix may differ from the ectocervix in terms of sex hormone sensitivity. However, although endometrial expression of estrogen and progesterone receptors has been shown to vary during the menstrual cycle ${ }^{21,22}$ no significant difference was demonstrated in hormone receptorpositive cell density between the follicular and luteal phases in both $\mathrm{TZ}$ and ectocervical biopsy specimens. These data are in agreement with previous studies that show no significant variation, within the menstrual cycle, in hormone receptor concentrations in vaginal tissues ${ }^{23}$ and in HPV-associated lesions, ${ }^{15}$ which suggests a lower sensitivity to menstrual cycle changes of genital squamous mucosa compared with glandular endometrial tissues.

Several studies have been performed previously with the objective to compare steroid hormone receptor expression between low/high-grade SIL and normal ectocervix. ${ }^{24-27}$ Despite some opposite results, it broadly appears that the expression of $\mathrm{E}_{2}-\mathrm{R}$ and $\mathrm{P}_{4}-\mathrm{R}$ is higher in SIL biopsies compared with normal ectocervix and 
increases with the grade of SIL. ${ }^{15}$ For example, it has been reported that $>60 \%$ of SIL biopsies express sex hormone receptors, strengthening the role of sex hormones in the development of SIL.

Because the expression of proliferation-associated antigens (such as $\mathrm{Ki}-67^{28}$ ) also increases during the cervical carcinogenesis, ${ }^{29}$ we compared the localization of $\mathrm{E}_{2}-\mathrm{R}, \mathrm{P}_{4}-\mathrm{R}$, and Ki-67 positive cells in ectocervix and $\mathrm{TZ}$ biopsy specimens. As previously reported, the expression of Ki-67 antigen was confined exclusively to the parabasal and basal cell layers of ectocervical and metaplastic cervical epithelium, ${ }^{29}$ whereas $E_{2}-R_{\text {and }} P_{4}-R$ receptors were also detected in intermediate cell layers in both localizations, which suggests a lack of a strict correlation between steroid receptor expression and cell proliferation. Although the co-expression of sex hormone receptors and $\mathrm{Ki}-67$ antigen has been reported in the cervix ${ }^{26}$ and in the endometrium, ${ }^{30}$ the correlation is not absolute, and cells in the quiescent GO phase of the cell cycle may also express $\mathrm{E}_{2}$ and $\mathrm{P}_{4}$ receptors.

There are several potential mechanisms by which sex hormones may facilitate the cervical carcinogenesis. The first one results from the property of sex hormones to induce HPV gene expression directly and/or indirectly through steroid response elements in the viral genome. ${ }^{14,15}$ Interestingly, the expression of estrogen receptor and HPV oncogenes has been demonstrated in the same basal cell population, ${ }^{31}$ and several hypotheses have been proposed to explain how estrogen receptor-signaling pathways may synergize with the cellular effects of the HPV16 oncoproteins. ${ }^{12}$ In agreement with these data, hormone receptors were detected in basal and parabasal cells in TZ epithelium, in which the target cells for HPV infection are presumably present. ${ }^{6,19}$

Fig 3: Immunohistochemical localization of estrogen ( $A$ and $B)$ and progesterone $(C$ and $D)$ receptors in ectocervical ( $A$ and $C$ ) and TZ epithelium ( $B$ and $D)$. (Original magnification, x500.)
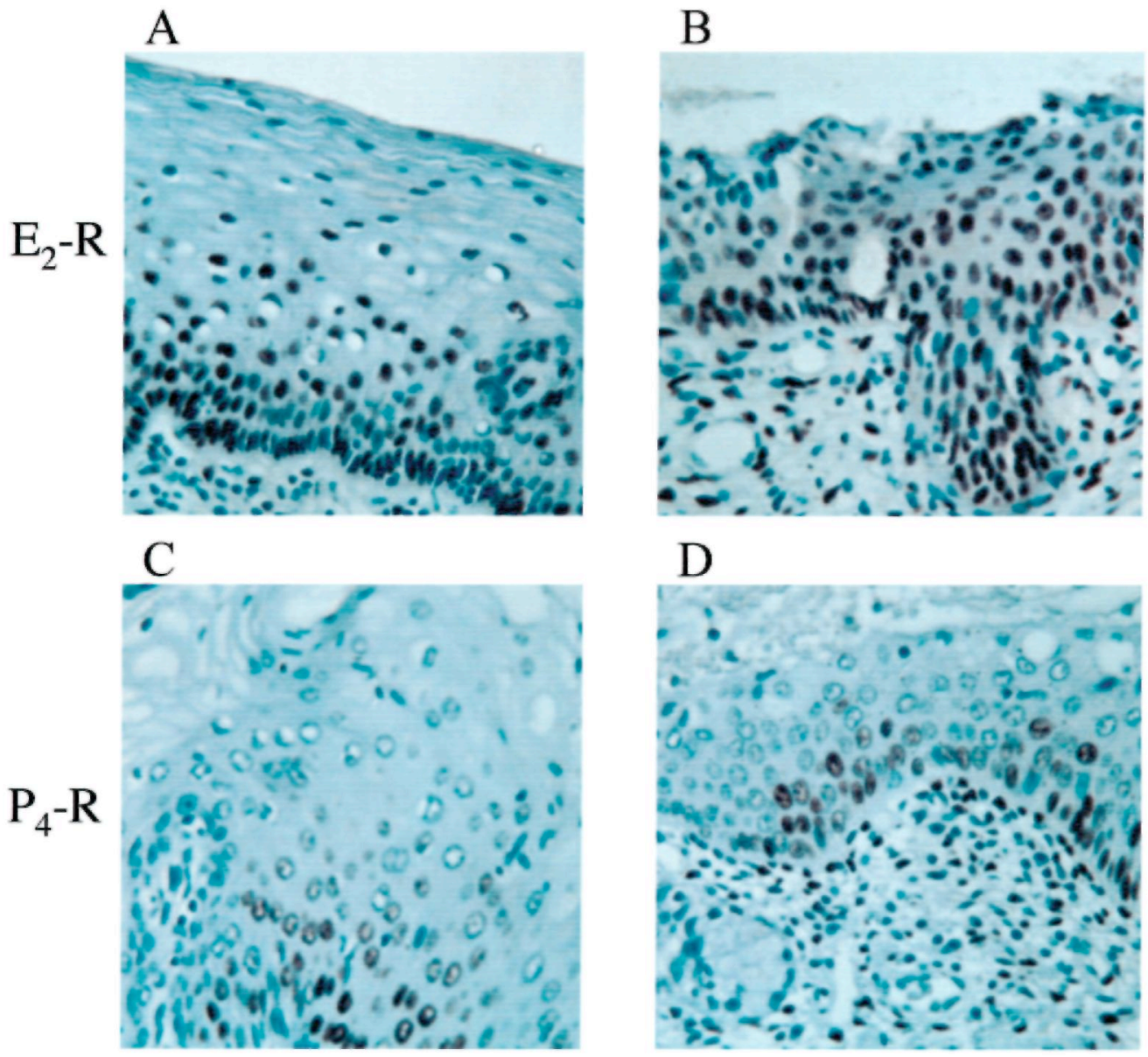
In addition to interactions between sex hormones and HPV oncoproteins, it is also possible that hormones sensitize the TZ to cervical cancer formation by altering the local immune microenvironment. The squamous epithelium of the cervix is composed not only of keratinocytes (the primary target of HPV) but also of a type of immature dendritic cells, the Langerhans' cells, which are important for the immunosurveillance of the cervical epithelium. ${ }^{32}$ It has been demonstrated that the keratinocyte/dendritic cell interactions in the TZ play a key role in the establishment of SIL and, in particular, that the density of Langerhans cells is reduced significantly in TZ compared with ectocervix. ${ }^{29}$ The production of cytokines/chemokines is necessary to maintain a balanced turnover of Langerhans cells and is most likely influenced by the complex differentiation state of keratinocytes, which is altered in metaplastic areas of the TZ and during cervical carcinogenesis. ${ }^{33-35}$ Interestingly, sex hormones have been shown to be involved directly in the regulation of the production of cytokines/chemokines and to be able to influence the migration and/or functional capacity of Langerhans cells/dendritic cells. ${ }^{36,37}$ It is therefore possible that estrogen and progesterone are involved in the HPV-related development of SIL by altering the cytokine/ chemokine-dependent interactions between keratinocytes and Langerhans cells/dendritic cells. This hormonal influence could be marked particularly in the TZ because of higher expression of sex hormone receptor expression compared with ectocervix. This hypothesis is now under active investigation.

In conclusion, our study demonstrated that estrogen and progesterone receptors are highly expressed in the $\mathrm{TZ}$ with immature squamous metaplasia compared with the ectocervix. This intrinsic feature of the TZ might explain partially the high susceptibility of this region to cervical HPV infections and associated (pre)neoplastic lesions and may be relevant for studies that aim to develop new antineoplastic or chemopreventive treatments.

\section{ACKNOWLEDGEMENTS}

Supported by the "Centre de Recherches Interuniversitaires en Vaccinologie"' (Convention 3073 with GlaxoSmithKline Beecham Biologicals and the Walloon Region) and the interuniversity attraction pole network (P5/31); the Belgian National Fund for Scientific Research (P. D., N. J.), and the "Centre de Recherches en Cancérologie Expérimentale'" in the University Hospital of Liège (V. M.).

\section{REFERENCES}

1. Burghardt E, Ostor AG. Site and origin of squamous cervical cancer: a histomorphologic study. Obstet Gynecol 1986;62:117-27.

2. Forsberg JG. Cervicovaginal epithelium: its origin and development. Am J Obstet Gynecol 1973;115:1025-43.

3. Hendrickson MR, Kempson RL. Normal histology of the uterus and fallopian tubes. In: Sternberg SS, edtior Histology for pathologists Philadelphia: Lippincott-Raven; 1997. p. 879-923.

4. Zur Hausen H. Papillomaviruses causing cancer: evasion from host-cell control in early events in carcinogenesis. J Natl Cancer Inst 2000;92:690-8.

5. de Vet HC, Sturmans F, Knipschild PG The role of cigarette smoking in the etiology of cervical dysplasia. Epidemiology 1994;5:631-3.

6. Crum CP Contemporary theories of cervical carcinogenesis: the virus, the host, and the stem cell. Mod Pathol 2000;13:243-51.

7. Tindle RW. Immune evasion in human papillomavirus-associated cervical cancer. Nat Rev Cancer 2002;2:59-65.

8. Schneider A, Hotz M, Gissmann L. Increased prevalence of human papillomavirus in the lower genital tract of pregnant women. Int $\mathbf{J}$ Cancer 1987;40:198-201.

9. Kedzia W, Gozdzicka-Jozefiak A, Kwasniewska A, Schmidt M, Miturski R, Spaczynski M. Relationship between HPV infection of the cervix and blood serum levels of steroid hormones among pre- and postmenopausal women. Eur J Gynecol Oncol 2000;21:177-9.

10. Salazar EL, Sojo-Aranda I, Lopez R, Salcedo M. The evidence for an etiological relationship between oral contraceptive use and dysplastic change in cervical tissue. Gynecol Endocrinol 2001;15:23-8.

11. Buckley C. The pathology of cervical intra-epithelial neoplasia, carcinoma and human papillomavirus infection. In: Stern PL, Stanley MA, editors. Human papillomavirus and cervical cancer biology and immunology Oxford: Oxford Medical; 1994. p. 1-27.

12. Elson DA, Riley RR, Lacey A, Thordarson G, Talamantes FJ, Arbeit JM. Sensitivity of the cervical transformation zone to estrogeninduced squamous carcinogenesis. Cancer Res 2000;60:1267-75. 
13. Tewari KS, Taylor JA, Liao SY, Disaia PJ, Burger RA, Monk BJ, et al. Development and assessment of a general theory of cervical carcinogenesis utilizing a severe combined immunodeficiency murine-human xenograft model. Gynecol Oncol 2000;77:137-48.

14. Yuan F, Auborn K, James C. Altered growth and viral gene expression in human papillomavirus type 16-containing cancer lines treated with progesterone. Cancer Invest 1999;17:19-29.

15. Monsonego J, Magdalena H, Catalan F, Coscas Y, Zerat L, Sastre X. Estrogen and progesterone receptors in cervical human papillomavirus related lesions. IntJ Cancer 1991;48:533-9.

16. Kim JW, Sung HR, Kim DK, Song CH. Estrogen and progesterone receptor assay in carcinoma of the cervix with monoclonal antibodies. Gynecol Oncol 1992;47:306-10.

17. Hoffman PG, Jones LA, Kuhn RW. Siiteri PK Progesterone receptors: saturation analysis by a solid phase hydroxylapatite adsorption technique. Cancer 1980;46:2801-4

18. Parkin DM, Laara E, Muir CS. Estimates of the worldwide frequency of sixteen major cancers in 1980. IntJ Cancer 1988;41:184-97.

19. Stanley MA. Immunobiology of papillomavirus infections. J Reprod Immunol 2001;52:45-59.

20. Sun Q, Tang SC, Pater MM, Pater A. Different HPV16 E6/E7 oncogene expression patterns in epithelia reconstructed from HPV16immortalised human endocervical cells and genital keratinocytes. Oncogene 1997;15:2399-409.

21. Ravn V, Rasmussen BB, Hojholt L, Barfoed M, Heiberg I, Svenstrup B, et al. Estrogen- and progesterone receptors in normal cycling endometrium as studied by end-point titration. Cell Tissue Res 1994;276:419-28.

22. Fujishita A, Nakane PK, Koji T, Masuzaki H, Chavez RO, Yamabe T, et al. Expression of estrogen and progesterone receptors in endometrium and peritoneal endometriosis: an immunohistochem-ical and in situ hybridization study Fertil Steril 1997;67:856-64.

23. Schwartz PE. The oestrogen receptor (ER) in vulva, vagina and ovary. Eur J Cancer 2000;36(Suppl):S31-2.

24. Nonogaki H, Fujii SF, Konishi I, Nanbu Y, Ozaki S, Ishikawa Y, et al. Estrogen receptor localization in normal and neoplastic epithelium of the uterine cervix. Cancer 1990;66:2620-7.

25. Henry RJW, Goodman JDS, Godley M, Raju KS, Coffer AI, King RJB. Immunohistochemical study of cytoplasmic oestradiol receptor in normal, dysplastic and malignant cervical tissue. BJOG 1988;95:927-32.

26. Konishi I, Fujii SF, Nonogaki H, Nanbu Y, Iwai T, Mori T Immunohistochemical analysis of estrogen receptors, progesterone receptors, Ki-67 antigen, and human papillomavirus DNA in normal and neoplastic epithelium of the uterine cervix. Cancer 1991;68: 1340-50.

27. Robertson DI, Paslawski D, Duggan MA, Stuart GCE, Nation JG. Estrogen and progesterone receptor, human papillomavirus, and DNA ploidy analysis in invasive carcinoma of the cervix in pregnancy. Anat Pathol 1993;100:18-21.

28. Gerdes J, Lemke H, Baisch H, Wacker HH, Schwab U, Stein H. Cell cycle analysis of a cell proliferation-associated human nuclear antigen defined by the monoclonal antibody Ki-67. J Immunol 1984;133:1710-5.

29. Al-Saleh W, Delvenne P, Arrese JE, Nikkels AF, Pierard GE, BoniverJ. Inverse modulation of intraepithelial Langerhans cell and stromal macrophage/dendrocyte populations in human papillomavirus-associated squamous intraepithelial lesions of the cervix. Virchows Arch $1995 ; 427: 41-8$

30. Pickartz H, Beckmann R, Fleige B, Due W, GerdesJ, Stein H. Steroid receptors and proliferative activity in non-neoplastic and neoplastic endometria. Virchows Arch A Pathol Anat Histopathol 1990 ;417:163-71.

31. Arbeit J, Howley P, Hanahan D. Chronic estrogen induced cervical and vaginal squamous carcinogenesis in HPV16 transgenic mice. Proc Natl Acad Sci U S A 1996;93:2930-5

32- Giannini SL, Hubert P, Doyen J, BoniverJ, Delvenne P. Influence of mucosal epithelium microenvironment on Langerhans' cells, implications for the development of squamous intraepithelial lesions of the uterine cervix. Int J Cancer 2002;97:654-9.

33. Smedts F, Ramaekers F, Troyanovsky M, Pruszczynski M, Robben H, Lane B, et al. Basal-cell keratins in cervical reserve cells and a comparison to their expression in cervical intraepithelial neoplasia. Am J Pathol 1992;140:601-13.

34. Smedts F, Ramaekers F, Leube RE, Keijser K, Link M, Vooijs P. Expression of keratins 1, 6, 15, 16, and 20 in normal cervical epithelium, squamous metaplasia, cervical intraepithelial neoplasia and cervical carcinoma. Am J Pathol 1993;142:403-12.

35. Hubert P, van den Brule F, Giannini SL, Franzen-Detrooz E, Boniver J, Delvenne P. Colonization of in vitro-formed cervical human papillomavirus- associated (pre) neoplastic lesions with dendritic cells:role of granulocyte/macro phage colony-stimulating factor. Am $\mathrm{J}$ Pathol 1999; $154: 775-84$

36. Schuurs AH, Verheul HA. Effects of gender and sex steroids on the immune response. J Steroid Biochem 1990;35:157-72- 
Published in: American Journal of Obstetrics and Gynecology (2003), vol. 189, iss. 6, pp. 1660-1665 Status : Postprint (Author's version)

37. Wira CR, Rossol RM, Kaushic C. Antigen-presenting cells in the female reproductive tract: influence of estradiol on antigen presentation by vaginal cells. Endocrinology 2000;141:2877-85. 